\title{
Induction of Apoptosis by Cold Atmospheric Pressure Plasma for Oral Squamous Cell Carcinoma Cells
}

\author{
Latha Ramireddy, ${ }^{\mathrm{a},{ }^{*}}$ Chih Ho Lai, ${ }^{\mathrm{b}}$ Bih Show Low, ${ }^{\mathrm{c}}$ Chuan Li, ${ }^{d}$ Jang Hsing Hsieh,,${ }^{\mathrm{a}, \mathrm{e}}$ \\ Jyh Wei Lee, ${ }^{\text {e } \& \text { Hui Yu Wu }}{ }^{\text {b }}$ \\ ${ }^{a}$ Center for Plasma and Thin Film Technologies, Ming Chi University of Technology, Taishan, \\ New Taipei City, Taiwan; 'Department of Microbiology and Immunology, Chang Gung University, \\ Taoyuan, Taiwan; 'Center for General Education, Chang Gung University, Taoyuan, Taiwan; \\ dDepartment of Biomedical Engineering, National Yang Ming University, Taipei, Taiwan; \\ eDepartment of Materials Engineering, Ming Chi University of Technology, Taishan, New Taipei \\ City, Taiwan \\ *Address all correspondence to: Latha Ramireddy, Research Fellow, Center for Plasma and Thin Film Technologies, \\ Ming Chi University of Technology, New Taipei City, Taiwan; Tel.: +886-2-2908-9899 \#4463; Fax: +886-2-2908-1843, \\ E-mail: latha.ramireddy@gmailcom
}

\begin{abstract}
Cold atmospheric pressure plasma (CAPP) techniques have developed rapidly during the last decades and have become an important field in plasma medicine. Plasma is ionized gas that is comprised of reactive atoms, molecules, ions, and radicals. CAPP generates various types of highly reactive oxygen and nitrogen species at room temperature that play an important part in biological applications including cancer therapy. In recent years, CAPP has gained increasingly more interest among cancer researchers, but the mechanism of CAPP's effect is not fully understood. The aim of this study is to investigate both the mechanism of CAPP on oral squamous cell carcinoma (OSCC) cells as well as plasma-induced radicals. We observe plasma-induced highly reactive species in a plasma plume and cell culture. A cell proliferation assay shows that CAPP significantly decreases proliferation of oral squamous cells in vitro. Western blot analysis shows cleavage of poly (ADP-ribose) polymerase protein after plasma treatment, indicating that CAPP can induce cell death via the apoptosis pathway. These findings show that CAPP could be used as an alternative adjuvant therapeutic tool for the treatment of OSCC.
\end{abstract}

KEY WORDS: cold plasma, oral squamous cell carcinoma, cell viability, apoptosis

\section{INTRODUCTION}

During the past decade, advances in physics and biotechnology research have led to the development of plasma medicine as an emerging field worldwide. Plasma that is generated at room temperature under laboratory conditions, known as cold atmospheric pressure plasma (CAPP), has tremendous applications for biomedical engineering. Recently, CAPP has been used in cancer treatment, ${ }^{1}$ sterilization, ${ }^{2}$ dental cavity treatment, ${ }^{3}$ wound healing, ${ }^{4}$ and blood coagulation, ${ }^{5}$ among other applications. But despite the immense range of biomedical applications, a cell-CAPP-specific mechanism has not been identified. Studies have shown, however, that increased intracellular reactive oxygen species (ROS) induce the apoptosis pathway. ${ }^{6,7}$ 
Oral squamous cell carcinoma (OSCC), a prevalent cancer worldwide, is a common head and neck cancer (HNC) that accounts for $\sim 3 \%$ of all newly diagnosed cancer cases and related deaths. Many treatment methods have been used, including surgery, chemotherapy, and radiation, but long-term survival rates have not improved in the past decade. ${ }^{8,9}$ In addition to the traditional cancer treatment methods, research has shown that CAPP may be an alternative. ${ }^{10,11}$ CAPP generates various types of species including ROS and reactive nitrogen species (RNS). These radicals induce cell death and trigger various signaling pathways. ${ }^{12,13}$ Several articles have explored different mechanisms, but molecular and cellular mechanisms remain elusive.

A recent study found that CAPP produces dose-dependent effects that increase cell proliferation and induce apoptosis. ${ }^{14}$ Appropriate plasma conditions such as those dependent on plasma dose and voltage value are required for the development of safe and more effective CAPP therapies. Another study reported that nonthermal atmospheric pressure plasma induces apoptotic cell death in OSCC cell lines. ${ }^{15}$ However, the effect of intracellular ROS quantity has not been explained. In this study, we designed a plasma jet to evaluate the effect of CAPP on OSCC cell lines. Our main aim is to investigate primary and molecular anticancer mechanisms and the effect of CAPP-induced radicals on OSCC cells.

\section{MATERIALS AND METHODS}

\section{A. Chemic als and Reagents}

We used Dulbecco's Modified Eagle Medium (DMEM) (HyClone cell culture products; GE Healthcare Life Sciences; Pittsburgh, PA); fecal bovine serum (FBS) (GE Healthcare); 3-(4,5-dimethylthiazol-2-yl)-2,5-diphenyltetrazolium bromide assay (MTT) (ThermoFisher Scientific; Waltham, MA); 2',7'-dichlorofluorescein diacetate (H2DCFDA) (Cayman Chemical; Ann Arbor, MI); $\beta$-actin antibody (Santa Cruz Biotechnology; Dallas, TX), antipoly (ADP-ribose) polymerase (PARP) (Proteintech Group, Inc.; Rosemont, IL); and horseradish peroxidase (HRP)-conjugated antirabbit or antimouse immunoglobulin antibodies (Santa Cruz Biotechnology).

\section{B. Cell Culture}

We purchased OSCC cells from the American Type Culture Collection. Cells were cultured at $37^{\circ} \mathrm{C}$ and $5 \% \mathrm{CO}_{2}$ at humidified conditions, in DMEM supplemented with $10 \% \mathrm{FBS}$ and $1 \%$ penicillin/streptomycin antibiotics. For further studies, we used cells grown to $90 \%$ confluence levels.

\section{CAPP Treatment}

The CAPP device was fabricated at Ming Chi University of Technology. The two electrodes were comprised of copper strips wrapped around the quartz tube, and distance between the high-voltage and grounded electrodes was $1.5 \mathrm{~cm}$. The grounded electrode was $0.2 \mathrm{~cm}$ 
away from the nozzle tip. Plasma treatment conditions were voltage $5.5 \mathrm{kV}$, frequency $10 \mathrm{kHz}$, helium gas of $99.99 \%$ purity flowing at $5 \mathrm{standard} \mathrm{L} / \mathrm{min}(\mathrm{slm}), 3 \mathrm{~cm}$ distance from liquid surface to tip, and 2-min treatment time. Figure 1 shows a schematic representation and image of the plasma jet. Cells $\left(5^{*} 10^{5}\right)$ were seeded in a 6-cm dish, treated with plasma for $2 \mathrm{~min}$, and incubated for $24 \mathrm{~h}$. Additional studies were performed after $24 \mathrm{~h}$.

\section{Optical Emission Spectroscopy}

The plasma produced various radicals that we estimated using an AvaSpec-ULS2048L optical emission spectroscope (Avantes; The Netherlands). Plasma jet emission spectra in 200- and 900-nm wavelengths were captured and analyzed using Avasoft 8 software (Avantes). For calculating peak intensities in optical spectra, we used $100 \mathrm{~ms}$ as the integration time for averaging.

\section{E. Cell Proliferation Assay}

We carried out a cell proliferation assay using the MTT assay according to the manufacturer's protocol. After $24 \mathrm{~h}$ of plasma treatment, we treated cells with MTT and incubated them for $3 \mathrm{~h}$ at $37^{\circ} \mathrm{C}$ and then dissolved formazan crystals in acidified isopropanol solution. The optical density was read at $570 \mathrm{~nm}$ using a microplate reader. Data were normalized with control $(100 \%)$ and shown as the viable cell percentage.
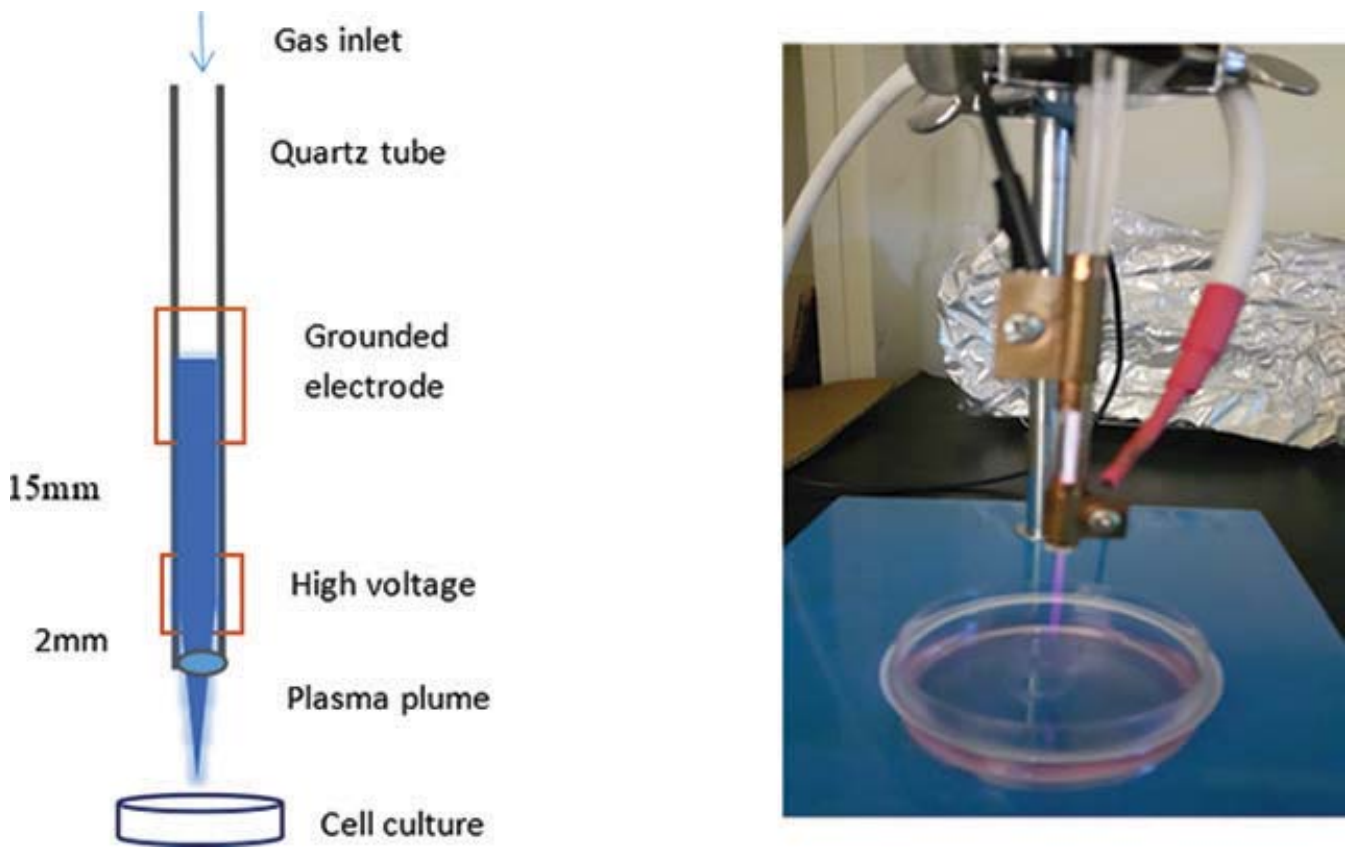

FIG. 1: Schematic diagram and image of the experimental setup 


\section{F. Westem Blot Assay}

After plasma treatment, cells were incubated for $24 \mathrm{~h}$ and then lysed with radioimmunoprecipitation buffer that had a protease/phosphatase inhibitor. Proteins were collected by centrifugation and separated using sodium dodecyl sulfate-polyacrylamide gel electrophoresis on tris-glycine gels and transferred to polyvinylidene fluoride membranes. The membranes were blocked with 5\% serum in tris-buffered saline and Tween 20 (TBST) for $1 \mathrm{~h}$ and incubated with primary antibody overnight at $4^{\circ} \mathrm{C}$. First washed with TBST, the membranes were then incubated with HRP-conjugated secondary antibodies for $1 \mathrm{~h}$ at room temperature. Proteins were visualized using enhanced chemiluminescence.

\section{G. ROS Detection}

ROS were measured using 2',7'-dichlorodihydrofluorescein diacetate (DCFDA). After plasma treatment, cells were incubated for $24 \mathrm{~h}$ and then incubated again with $5 \mathrm{um}$ DCFDA for $30 \mathrm{~min}$ at $37^{\circ} \mathrm{C}$. We measured fluorescence intensity at 485 and $535 \mathrm{~nm}$ using a microplate reader according to the manufacturer's protocol.

\section{RESULTS AND DISC USSION}

We analyzed a plasma-emitted spectrum wavelength of 200-900 nm to identify ROS and RNS generated by CAPP. Figure 2 shows emission spectra of He that is generated at flow $5 \mathrm{slm}$, voltage $5.5 \mathrm{kV}$, and frequency $10 \mathrm{kHz}$. We measured emission lines of the $\mathrm{OH}$ radical at $309 \mathrm{~nm}$ and an atomic oxygen peak at $673 \mathrm{~nm}$. We assessed 330-400 nm $\mathrm{N}_{2}$ corresponding peaks that occurred due to the mixing of He with ambient air surrounded by the plasma jet. ROS and RNS have important roles in biomedical applications such as wound healing, bacterial deactivation, and sterilization.,16,17 To verify the effect of plasma treatment on OSCC cell lines, we performed a cell proliferation assay using MTT $24 \mathrm{~h}$ after plasma treatment. The results, shown in Fig. 3, show that plasma

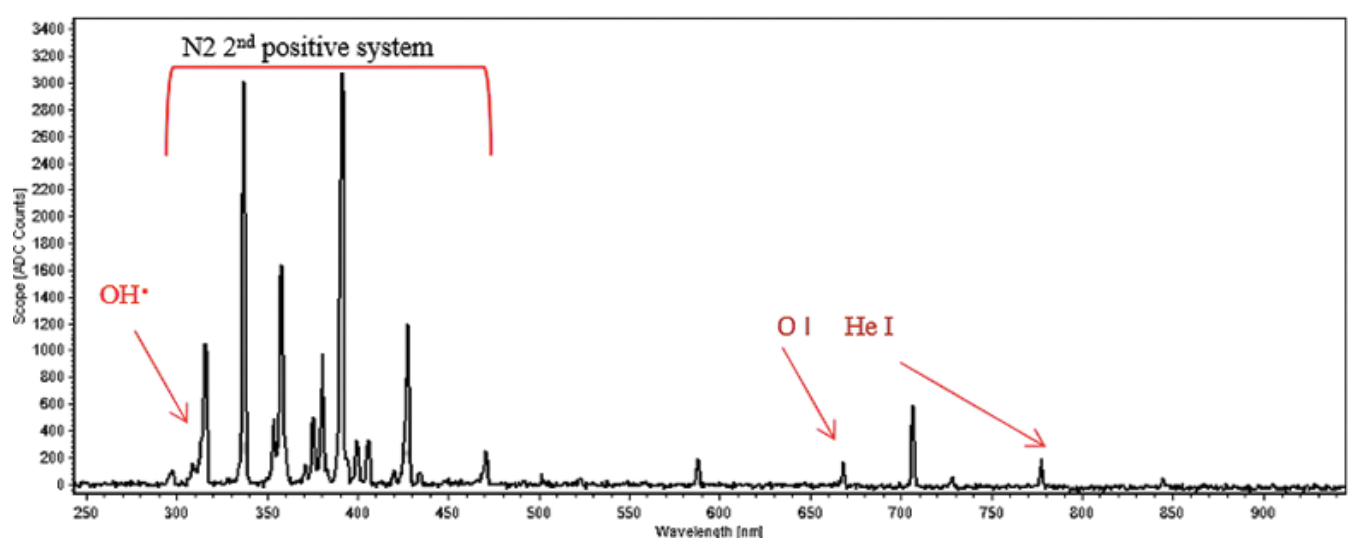

FIG. 2: Optical emission spectrum of He plasma jet 
treatment reduced cell proliferation by $\sim 38 \%$, indicating that CAPP produced an anticancer effect when cancer cells were exposed to plasma.

The main aim of this study was to investigate the effect of cold atmospheric plasma on oral squamous cells. A number of studies have suggested a possible molecular mechanism of CAPP in different cancer cell lines. Plasma triggers several signaling pathways, including c-Jun amino-terminal kinases (JNKs), P38, mitogen-activated protein kinase ${ }^{18}$ nuclear transcription factor $\kappa \mathrm{B}(\mathrm{NF}-\kappa \mathrm{B})$ pathways in fibroblast cells (L929), ${ }^{19}$ $\mathrm{p}$-focal adhesion kinases, matrix metalloproteinase pathways in oral squamous cells, ${ }^{20}$ and ataxia-telangiectasia mutated/P53 pathways in HNC cells. ${ }^{15}$ To study the anticancer mechanism of plasma-treated OSCC cells, at $24 \mathrm{~h}$ after plasma treatment proteins were extracted and Western blot analysis was performed. We used actin as the internal control. To determine the extent of apoptosis, we assayed PARP protein, which is a known apoptosis marker, and observed the CAPP effect on OSCC cells. The mechanism involved was cleavage of PARP (Fig. 4). Similar pathway mechanisms were previously observed in ovarian cancer ${ }^{21}$ and glioma ${ }^{22}$ cells. We observed cleaved PARP protein in

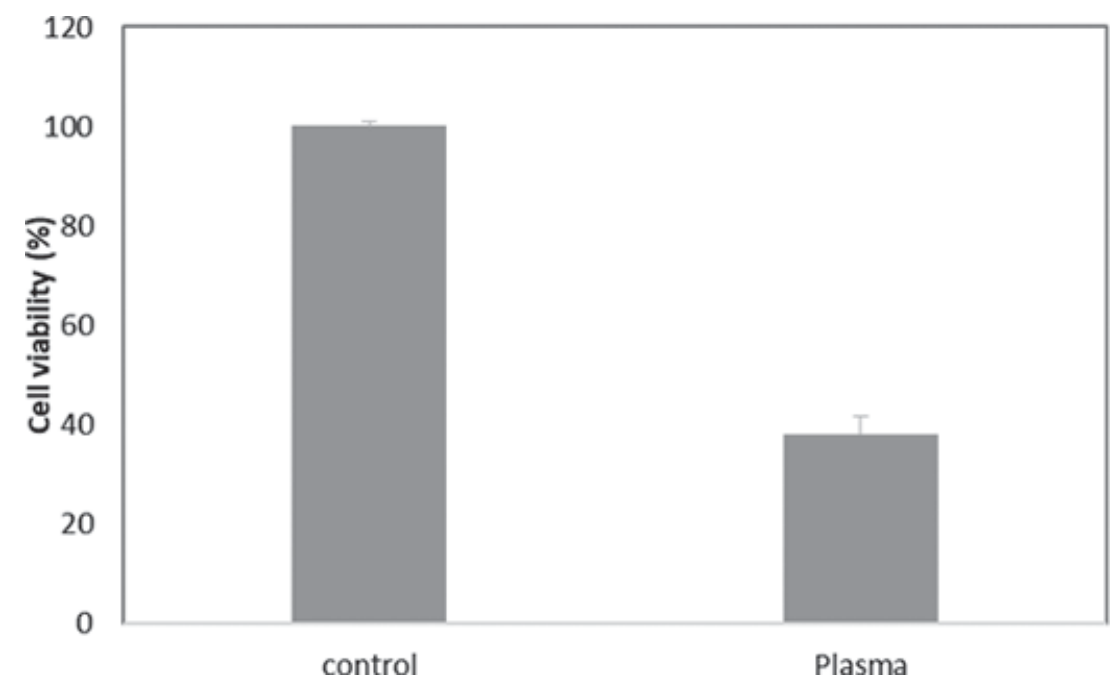

FIG. 3: Cell viability assay results measured $24 \mathrm{~h}$ after plasma treatment

\section{Control Plasma}

\section{$116 \mathrm{KDa}$ $89 \mathrm{kDa}$}

$43 \mathrm{kDa}$

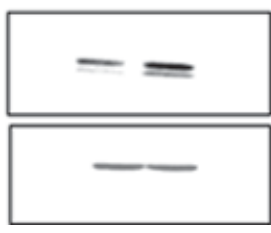

Full length Parp Cleaved Parp

Actin

FIG. 4: Western blot analysis indicates apoptosis at $24 \mathrm{~h}$ after plasma treatment 


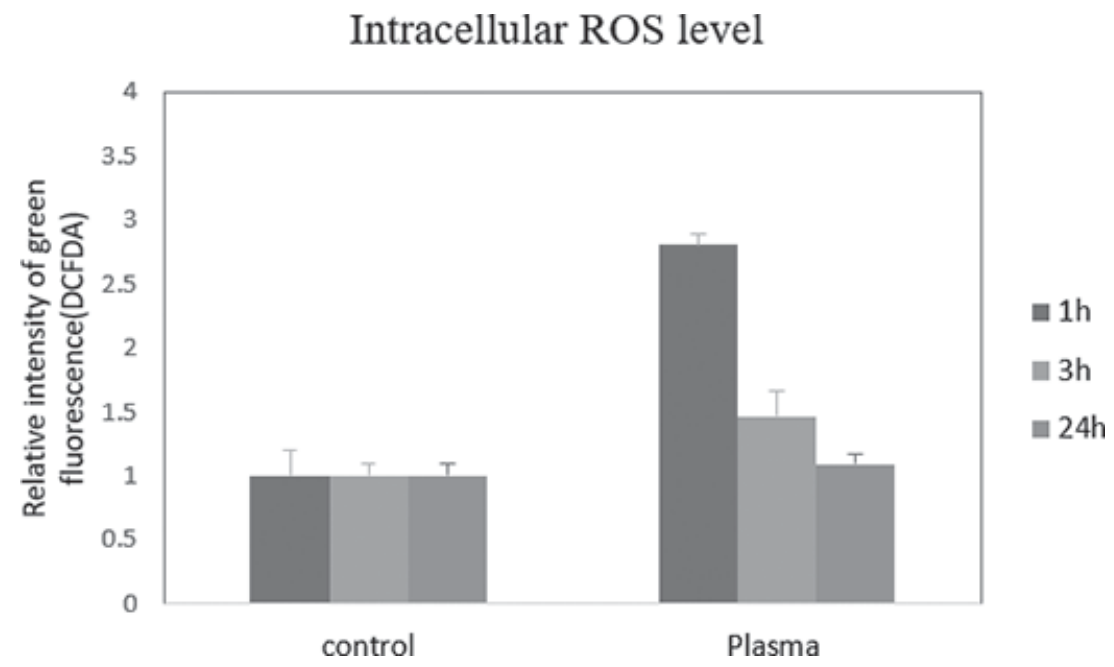

FIG. 5: Generation of ROS by air plasma. Intracellular ROS were determined using the ROS probe DCFDA.

plasma-treated OSCC cells (Fig. 4). Results confirmed that CAPP induced cell death via the apoptosis pathway in OSCC cell lines.

We further measured intracellular ROS, including hydrogen peroxide $\left(\mathrm{H}_{2} \mathrm{O}_{2}\right)$, hydroxyl radicals $\left(\mathrm{OH}^{-}\right)$, and singlet oxygen $(\cdot \mathrm{O} 2)$, using the DCFDA probe (shown in Fig. 5). Results showed that plasma treatment induced intracellular ROS levels to increase, and after $3 \mathrm{~h}$, ROS levels decreased. After $24 \mathrm{~h}$, intracellular ROS levels were reached to control (nontreatment) basal level. These results suggest that plasma treatment increases intracellular ROS levels (Fig. 5). To our knowledge, this is the first study explaining the effects of CAPP on intracellular ROS in oral squamous cells. A previous study showed that a plasma-induced apoptosis pathway was activated by the increase of intracellular ROS. ${ }^{23}$

\section{CONCLUSION}

This study demonstrates induced cell death of oral squamous carcinoma cells after increases in intracellular ROS. ROS generation is important for its anticancer effects. PARP cleavage was observed in plasma-treated oral squamous cells. In summary, CAPP can be used as a potential anticancer tool because it triggers the apoptosis pathway in OSCC cells after increased intracellular ROS.

\section{ACKNOWRDGMENT}

This work is financially supported by the Center for Plasma and Thin Film Technologies at Ming Chi University of Technology, Taiwan. 


\section{REFERENCES}

1. Kong MG, Kroesen G, Morfill G, Nosenko T, Shimizu T, van Dijk J, Zimmermann JL. Plasma medicine: An introductory review. New J Phys. 2009;11(11):115012.

2. Mai-Prochnow A, Murphy AB, McLean KM, Kong MG, Ostrikov KK. Atmospheric pressure plasmas: Infection control and bacterial responses. Int J Antimicrob Agents. 2014;43(6):508-17.

3. Rupf S, Lehmann A, Hannig M, Schafer B, Schubert A, Feldmann U, Schlindler A. Killing of adherent oral microbes by a non-thermal atmospheric plasma jet. J Med Microbiol. 2010;59(Pt 2):206-12.

4. Nosenko T, Shimizu T, Morfill GE. Designing plasmas for chronic wound disinfection. New J Phys. 2009;11(11):115013.

5. Fridman G, Friedman G, Gutsol A, Shekhter AB, Vasilets VN, Fridman A. Applied plasma medicine. Plasma Proc Polym. 2008;5(6):503-33.

6. Sensenig R, Kalghatgi S, Cerchar E, Fridman G, Shereshevsky A, Torabi B, Arjunan KP, Podolsky E, Fridman A, Friedman G, Azizkhan-Clifford J, Brooks AD. Non-thermal plasma induces apoptosis in melanoma cells via production of intracellular reactive oxygen species. Ann Biomed Eng. 2011;39(2):674-87.

7. Vandamme M, Robert E, Lerondel S, Sarron V, Ries D, Dozias S, Sobilo J, Gosset D, Kieda C, Legrain B, Pouvesle JM, Pape AL. ROS implication in a new antitumor strategy based on nonthermal plasma. Int J Cancer. 2012;130(9):2185-94.

8. Chang JW, Kang SU, Shin YS, Seo SJ, Kim YS, Yang SS, Lee JS, Moon E, Lee K, Kim CH. Combination of NTP with cetuximab inhibited invasion/migration of cetuximab-resistant OSCC cells: Involvement of NF-KB signaling. Sci Rep. 2015;5:18208.

9. Argiris A, Karamouzis MV, Raben D, Ferris RL. Head and neck cancer. Lancet. 2008;371(9625): 1695-709.

10. Keidar M, Shashurin A, Volotskova O, Stepp MA, Srinivasan P, Sandler AD, Trink B. Cold atmospheric plasma in cancer therapy. Phys Plasmas. 2013;20(5):057101.

11. Kim SJ, Chung TH. Plasma effects on the generation of reactive oxygen and nitrogen species in cancer cells in-vitro exposed by atmospheric pressure pulsed plasma jets. Appl Phys Lett. 2015;107(6):063702.

12. Ahn HJ, Kim KI, Kim G, Moon E, Yang SS, Lee JS. Atmospheric-pressure plasma jet induces apoptosis involving mitochondria via generation of free radicals. PLoS One. 2011;6(11):e28154.

13. Kim CH, Kwon S, Bahn JH, Lee K, Jun SI, Rack PD, Baek SJ. Effects of atmospheric nonthermal plasma on invasion of colorectal cancer cells. Appl Phys Lett. 2010;96(24):243701.

14. Kalghatgi S, Kelly CM, Cerchar E, Torabi B, Alekseev O, Fridman A, Friedman G, Azizkhan-Clifford J. Effects of non-thermal plasma on mammalian cells. PLoS One. 2011;6(1):e16270.

15. Chang JW, Kang SU, Shin YS, Kim KI, Seo SJ, Yang SS, Lee JS, Moon E, Baek SJ, Lee K, Kim CH. Non-thermal atmospheric pressure plasma induces apoptosis in oral cavity squamous cell carcinoma: Involvement of DNA-damage-triggering sub- $\mathrm{G}_{1}$ arrest via the $\mathrm{ATM} / \mathrm{p} 53$ pathway. Arch Biochem Biophys. 2014;545:133-40.

16. Heaselgrave W, Shama G, Andrew PW, Kong MG. Inactivation of Acanthamoeba spp. and other ocular pathogens by application of cold atmospheric gas plasma. Appl Env Microbiol. 2016;82(10):3143-8.

17. Goldman R, Pollack S. Electric fields and proliferation in a chronic wound model. Bioelectromagnetics. 1996;17(6):450-7.

18. Ahn HJ, Kim KI, Hoan NN, Kim CH, Moon E, Choi KS, Yang SS, Lee JS. Targeting cancer cells with reactive oxygen and nitrogen species generated by atmospheric-pressure air plasma. PLoS One. 2014;9(1):e86173.

19. Liu JR, Xu GM, Shi XM, Zhang GJ. Low temperature plasma promoting fibroblast proliferation by activating the NF-KB pathway and increasing cyclin D1 expression. Sci Rep. 2017;7(1):11698.

20. Kang SU, Seo SJ, Kim YS, Shin YS, Koh YW, Lee CM, Yang SS, Lee JS, Moon E, Kang H, Ryeo JB, Lee Y, Kim CH. Comparative effects of non-thermal atmospheric pressure plasma on migration and invasion in oral squamous cell cancer, by gas type. Yonsei Med J. 2017;58(2):272-81.

Volume 8, Issue 4, 2018 
21. Iseki S, Nakamura K, Hayashi M, Tanaka H, Kondo H, Kajiyama H, Kano H, Kikkawa F, Hori M. Selective killing of ovarian cancer cells through induction of apoptosis by nonequilibrium atmospheric pressure plasma. Appl Phys Lett. 2012;100(11):113702.

22. Koritzer J, Boxhammer V, Schafer A, Shimizu T, Klampfl TG, Li YF, Welz C, Schwenk-Zieger S, Morfill GE, Zimmermann JL, Schlegel J. Restoration of sensitivity in chemo-resistant glioma cells by cold atmospheric plasma. PLoS One. 2013;8(5):e64498.

23. Ishaq M, Kumar S, Varinli H, Han ZJ, Rider AE, Evans MD, Murphy AB, Ostrikov K. Atmospheric gas plasma-induced ROS production activates TNF-ASK1 pathway for the induction of melanoma cancer cell apoptosis. Mol Biol Cell. 2014;25(9):1523-31. 